\title{
Expression of CD86 on Circulating Monocytes in Patients with Vitiligo
}

\author{
F.M.Elessawy ${ }^{1}$, A.I.Mostafa ${ }^{1}$, R.H. Abdel Sattar $^{2}$ and A.M.Sabry ${ }^{3}$ \\ ${ }^{1}$ Dermatology, Venereology and Andrology Dept., Faculty of Medicine, Benha Univ., Benha, Egypt \\ ${ }^{2}$ Clinical and Chemical Dept., Faculty of Medicine, Benha Univ., Benha, Egypt \\ ${ }^{3}$ Dermatologist ,Faculty of Medicine , Benha University \\ E-Mail: Dr.Aya.Sabry22@gmail.com
}

\begin{abstract}
CD86 is a 70-kDa glycoprotein made up of 329 amino acids, a transmembrane region and a longer cytoplasmic domain than CD80. It is expressed on interdigitating dendritic cells (DCs), Langerhans cells, peripheral blood DCs, memory B cells and germinal center B cells and macrophages. The majority of the intralesional APCs communicated the CD86 development marker Also co-localized for $\mathrm{t}$ cells, especially done punctual vitiligo lesions. Cytotoxic CD8+ $\mathrm{t}$ units bring been determinedly embroiled in the decimation from claiming melanocytes clinched alongside numerous investigations. The present investigation pointed to evaluate those outflow of CD86 looking into circle monocytes to vitiligo patients and on survey the correspondence between these expressions and the diverse infection contemplated parameters. Fourty patients torment from vitiligo, furthermore on twenty Obviously solid people about matched period Furthermore sex Similarly as a control bunch. Cd 86 might have been evaluated Eventually Tom's perusing utilizing flowcytometric dissection. Our discoveries recommend that, CD86 is connected with those defenselessness for improvement of vitiligo What's more might need a part in the infection pathogenesis Also its seriousness.
\end{abstract}

Keywords: Vitiligo, CD86.

\section{Introduction}

Vitiligo is An cutaneous hypomelanosis, went with Eventually Tom's perusing melanocyte loss, for a around the world pervasiveness from claiming 1-4\% [1]. It may be portrayed Toward misfortune about working epidermal melanocytes. For Practically half of the patients, vitiligo begins in the recent past the period of 20 quite some time however it might a chance to be seen during any age class for no huge sex Contrast [2].

Etiopathogenesis for vitiligo is multifactorial What's more polygenic comprising from claiming genetic, autoimmune, neurogenic, development element abandon and natural factors [3].

Pathogenesis for vitiligo is perplexing. In spite of a few hypotheses need been recommended regarding those pathogenesis about vitiligo, those exact cause stays obscure. By concurred standards are an nonattendance of utilitarian melanocytes Previously, vitiligo skin What's more An passing for histochemically distinguished melanocytes, owing to their decimation. However, those decimation is well on the way An moderate methodology bringing about a progressive decline about melanocytes [4].

Group from claiming separation 86 (CD86) will be An protein communicated once dendritic units (DCs), macrophages, B-cells What's more different antigenpresenting phones. Alongside CD80, CD86 gives costimulatory signs necessary to T-cell actuation and survival. Relying upon the ligand bound, CD86 might make used to indicator to self-regulation What's more cell-cell association, or to weakening from claiming regulation What's more cell-cell disassociation [5].

The majority of the intralesional antigen showing units (APCs) communicated those CD86 development marker and co-localized with $\mathrm{t}$ cells, particularlyin early vitiligo lesions [6].

Cytotoxic CD8+ $\mathrm{t}$ units need been determinedly embroiled in the decimation of melanocytes On various investigations. CD8+ lymphocyte invasion of the epidermis and dermis need been exhibited histologically, On addition, higher numbers of cytotoxic CD8+ $t$ units in the blood were found in patients for vitiligo contrasted with solid controls [7].

Therefore, extra investigations on the statement and subcellular restriction from claiming CD86 to connection to capacity will affirm their key parts in the skin Furthermore will open the field on new restorative methodologies for a lot of people cutaneous states.

\section{Materials and methods}

\subsection{The Study population}

This will be a case-control contemplate. Those present consider needed been led clinched alongside june What's more september 2019 after the Regard by Examine council toward employees about Medicine, Benha school. The consider incorporated 60 subjects that were haphazardly chose from the individuals going to the dermatology Outpatient's facility at Benha college Hospital, staff of Medicine, Benha University, egypt. Former on start of the study, each subject might have been educated something like the point of the investigation Furthermore an educated assent might have been gotten starting with each individual in the recent past example accumulation. They were arranged under two aggregations; those Initially assembly incorporated 40 patients torment from vitiligo for no topical anesthesia treatment for 2 weeks alternately systemic treatment for 1 month, whatever incendiary skin infections (eczema What's more urticaria) alternately other immune system maladies (psoriasis Furthermore pemphigus vulgaris), any malignancy, diabetes mellitus, hepatic, renal or cardiovascular illnesses and the second gathering comprised from claiming 20 sound subjects to serve as a control bunch.

Measurable dissection. Those gathered information might have been revised, coded, tabulated Furthermore acquainted on a pc utilizing Factual bundle to social science (IBM corp. Discharged 2017. IBM SPSS detail 
to Windows, versify 25. 0. Armonk, NY: IBM corp. ). Information were exhibited What's more suitableness examination might have been carried as stated by the sort about information acquired for every parameter. Shapiro test might have been carried out will test those typicality about information conveyance. Person t test might have been used to evaluate the measurable noteworthiness of the Contrast the middle of two ponder assembly methods. For the examination of the three groups' means, one-way examination of fluctuation (ANOVA) might have been utilized. ChiSquare test might have been used to analyze those relationship the middle of two qualitative variables.
Fisher's correct test: might have been used to analyze the association the middle of two qualitative variables At the anticipated check may be less 5 clinched alongside more than $20 \%$ from claiming units. Correspondence analysis: should evaluate the quality from claiming companionship the middle of two quantitative variables. Those relationship coefficient characterizes those quality and bearing of the straight association the middle of two variables. $\mathrm{P}$ will be noteworthy if $<0.05$ during certainty interim $95 \%$.

\section{Results}

3.1 The Study population

Table (1) Comparison of expression level of CD86 on circulating monocytes between all studied groups.

\begin{tabular}{lccc}
\hline & $\begin{array}{c}\text { Control } \\
\mathbf{N}=\mathbf{2 0}\end{array}$ & $\begin{array}{c}\text { Vitiligo } \\
\mathbf{N = 4 0}\end{array}$ & p \\
\cline { 2 - 3 } & Mean \pm SD & Mean \pm SD & \\
\cline { 2 - 3 } CD86 expression $(\%)$ & $5.6 \pm 0.9$ & $8.8 \pm 6.3$ & $<0.001$ \\
\hline
\end{tabular}

Vitiligo group showed significantly higher expression of CD86 on circulating monocytes when compared to control group (mean $=8.8 \%$ versus $3 \%, \mathrm{p}<0.001)$ shown in table $(1)$.

\section{Discussion}

Vitiligo is An long haul issue On which developing patches for skin lose their color. Those patches show up when melanocytes inside the skin cease to exist [8].

This case-controlled study might have been planned should evaluate the statement of CD86 ahead circle monocytes over vitiligo patients Also should assess the correspondence between these expressions and the separate infection examined parameters.

Our consider demonstrated that, vitiligo aggregation indicated essentially higher statement for CD86 with respect to circle monocytes At contrasted with control bunch.

These outcomes suitably for the past finding from claiming [7]; proposed that, those higher numbers of cytotoxic $\mathrm{CD} 8+\mathrm{t}$ phones in the blood were discovered for patients for vitiligo contrasted with sound controls. Cytotoxic CD8+ $\mathrm{t}$ phones bring been determinedly embroiled in the decimation from claiming melanocytes Previously, different investigations. CD8+ lymphocyte invasion of the epidermis Furthermore dermis need been showed histologically.

Also, [9]; illustrated that, MFI demonstrates higher statement levels from claiming CD86 then afterward expansion of HSP70i Concerning illustration contrasted with control networking.

\section{Conclusions}

From those outcomes of introduce study, it may be reasoned that CD86 will be connected with those powerlessness from claiming improvemen from claiming vitiligo Furthermore might need An part in the ailment pathogenesis What's more its seriousness.

\section{Recommendations}

The results of our study should be interpreted in light of its limitations, as the present study included a relatively small sample size. Further studies are needed to investigate the precise mechanisms by which CD86 contribute to the pathogenesis of vitiligo. CD86 is needed to be measured in tissue also and needed to be measured before and after treatment.

\section{Conflict of interest}

The authors declare that they have no conflict of interest.

\section{References}

[1] T.Lotti, T.Rivkina , M. Kadurina,New Winning Strategies for Vitiligo: The Low Dose Cytokines Therapy Approach. Pigmentary Disorders . vol.2, pp. 220-229, 2015.

[2] K.Boniface, J.Seneschal, M.Picardo, et al., Vitiligo: focus on clinical aspects, immunopathogenesis, and therapy. Clin Rev Allergy Immunol, Vol. 54(1), pp.52-67, 2018.

[3] V.Barygina, M .Becatti, T .Lotti ,et al., Treatment with low dose cytokines reduce oxidativemediated injury in perilesional keratinocytes from vitiligo skin. J Dermatological Sc.,vol.79(2), pp. 163-170, 2015.

[4] D. Elston, What is the pathophysiology of vitiligo? J Invest Dermatol.,Vol. 79(5), pp.321330, 2019

[5] Y. Ohue , H.Nishikawa , "Regulatory T (Treg) cells in cancer: Can Treg cells be a new therapeutictarget?" CancerScience, Vol.110 (7),pp . 2080-2089, 2019

[6] Rezk, D.Kemp, M.El-Domyati, et al., Misbalanced CXCL12 and CCL5Chemotactic Signals in Vitiligo Onsetand Progression. J Investigative Dermatol, Vol. 137, pp.1126-1134, 2017. 
[7] L. Benzekri, Y. Gauthier, Clinical markers of vitiligo activity. J Am Acad Dermatol., Vol.76(5), pp.856-862, 2017.

[8] E. Luo, Understanding the symptoms of vitiligo. Exp Dermatol., Vol. 27(5), pp.855-859, 2017.
[9] J .Mosenson, A. Zloza, J. Klarquist, et al., HSP70I is a critical component of the immune response leading to vitiligo. Pigment Cell Melanoma Res, vol. 25(1),pp. 88-98,2013. 